\title{
TIPE SEDIMEN DI DASAR PERAIRAN ARAFURA
}

\author{
Suprapto*) \\ -) Peneliti pada Balai Riset Perikanan Laut, Muara Baru-Jakarta
}

\begin{abstract}
ABSTRAK
Setiap wilayah perairan mempunyai tipe sedimen berbeda-beda sesuai dengan letak geografis dan topografi. Informasi tipe sedimen tersebut, sangat penting untuk diketahui karena aspek ini dapat digunakan sebagai data dukung bagi pengkajian sumber daya ikan demersal di suatu perairan. Berkaitan dengan hal tersebut maka makalah ini akan menginformasikan tipe sedimen di perairan Arafura yang diperoleh dari salah satu kegiatan riset oseanografi yang dilakukan pada bulan Oktober 2003. Hasil pengamatan memperlihatkan bahwa sedimen yang menyusun dasar perairan Arafura didominasi oleh tipe berliat $(48 \%)$ yang menyebar pada sebagian besar perairan dekat pantai terutama sekitar muara Sungai Digul, sedangkan pada perairan menjauhi pantai, pada umumnya berupa campuran liat berpasir yang mendominasi sekitar $29,6 \%$; lempung berpasir $11 \%$; dan yang bertipe pasir relatif jarang.
\end{abstract}

KATA KUNCI: sedimen, perairan Arafura

\section{PENDAHULUAN}

Informasi tentang tipe sedimen di dasar perairan laut merupakan salah satu data dasar dari aspek fisik perairan yang sangat penting dalam mendukung kegiatan pengkajian sumber daya ikan, hal tersebut karena seringkali mempunyai kaitan erat dengan keberadaan populasi ikan demersal terutama berperan menentukan pola distribusi, dominasi jenis maupun besar biomassa ikan-ikan yang hidup di sekitar dasar perairan.

Hubungan keterkaitan antara tipe sedimen dengan keberadaan populasi ikan menurut Nybaken (1988) lebih didasari oleh naluri adaptasi ikan terhadap ketersediaan makanan maupun terhadap kondisi lingkungan perairan yang sesuai untuk hidup. Kelompok jenis ikan yang hidup di dekat dasar perairan (demersal) cenderung menyukai lingkungan substrat dasar yang mempunyai tipe sedimen tertentu, hal tersebut selain kualitas perairan mendukung bagi kelangsungan hidup, juga terkait dengan ketersediaan pakan alami kesukaan yaitu berupa berbagai organisme dasar (bentos). Distribusi populasi bentos di dasar perairan tersebut ditentukan oleh tipe sedimen, oleh karena itu tipe sedimen dasar perairan tersebut secara tidak langsung akan mempengaruhi dinamika populasi ikan demersal.

Beberapa hasil penelitian yang secara jelas memberikan petunjuk keterkaitan antara sedimen dan keberadaan populasi ikan demersal adalah kegiatan penangkapan ikan menggunakan alat tangkap jaring pukat dasar (bottom trawl). Widodo (1979) dan Martosubroto \& Badrudin (1984) mengatakan bahwa komposisi jenis ikan yang tertangkap dan laju tangkap selalu memperlihatkan hasil yang berbeda-beda untuk setiap kedalaman yang berbeda. Indikasi tersebut diprediksi selain dipengaruhi oleh faktor tekanan, juga karena lingkungan substrat dasar yang cenderung mempunyai tipe sedimen yang berbeda pula. Rosyid (1995) dalam kajian serupa terhadap alat tangkap mini trawl yang banyak dioperasikan nelayan di perairan Rembang-Kendal (Jawa Tengah) juga menunjukkan indikasi demikian, yakni hasil tangkapan ikan yang paling tinggi pada umumnya berada pada kedalaman 20 sampai dengan $\mathbf{4 0} \mathrm{m}$ di mana tipe sedimen didominasi oleh tekstur pasir berlumpur dan komposisi jenis ikan yang tertangkap bervariasi, sebaliknya hasil tangkapan terendah apabila substrat dasar tersebut bertipe lumpur, jenis ikan yang dominan pada habitat ini adalah kelompok suku Scianidae (ikan tiga waja). Demikian pula, hasil kajian Soedharma (1972) pada pengamatan terhadap komposisi jenis hasil tangkapan udang di perairan Kalimantan Selatan. Jenis udang windu (Penaeus monodon) dan udang bago (Penaeus semiculcatus) banyak tertangkap pada perairan yang mempunyai tipe sedimen terdiri atas lempung liat bercampur pasir, sedangkan udang jerbung (Penaeus merguensis) dan udang api-api (Metapeneus monoceros) tertangkap pada hampir semua bentuk tipe substrat dasar. Gambar 1 menunjukkan beberapa jenis ikan sesuai dengan jenis atau tipe sedimen.

Tipe sedimen pada setiap wilayah perairan berbeda-beda tergantung topografi dan letak georafis. Menurut Widodo (1979) di perairan Laut Jawa sebagian besar (58\%) tipe dasar terdiri atas lumpur, sedangkan sisa $42 \%$ terdiri atas pasir, campuran pasir lumpur, dan batu kerikil (gravel). Di 


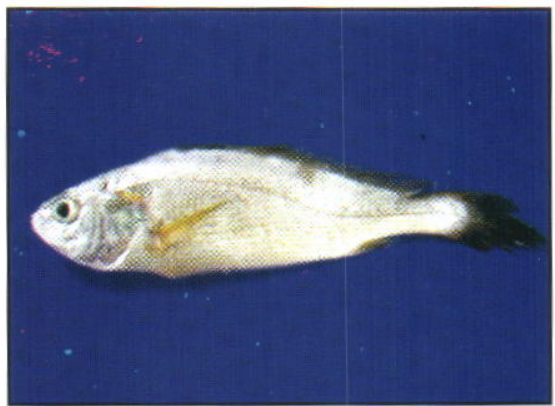

Ikan gulamah atau tiga waja (Scianidae) habitat pada substrat lumpur

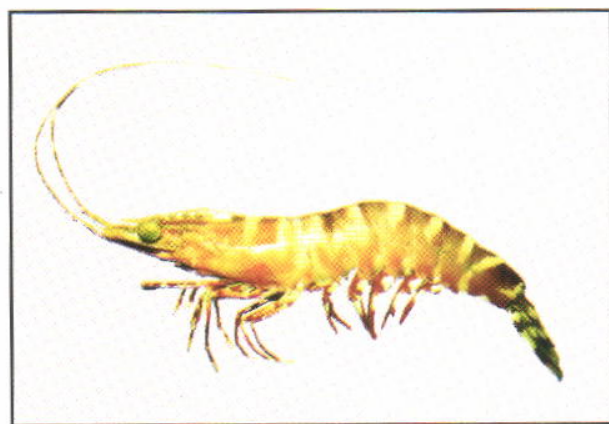

Udang windu (Penaeus monodon),

menyukai tipe sedimen lempung liat berpasir

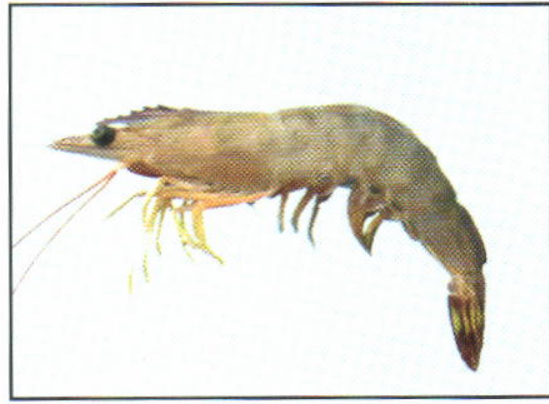

Udang jerbung (Penaeus merguiensis)

menyukai tipe sedimen liat bercampur pasir, lumpur

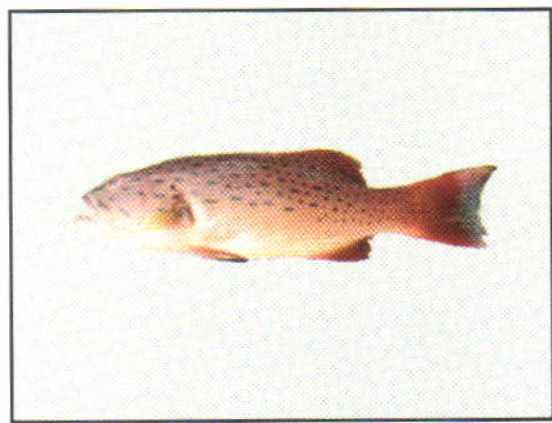

Kerapu sunu (Plectropomus sp.)

menyukai tipe sedimen pasir campur karang

Gambar 1. Beberapa jenis ikan dan udang, hidup pada berbagai jenis tipe sedimen.

dasar perairan Teluk Jakarta, sebagian besar didominasi oleh lumpur $(62 \%)$, pasir $35 \%$, dan kerikil 3\% (Ongkosongo et al., 1979). Di perairan Sorong menurut Hermanto et al. (1987), tipe sedimen didominasi pasir, terutama pasir berukuran halus.

Mengingat pentingnya informasi sedimen dalam mendukung pengkajian stok sumber daya ikan di suatu perairan, maka dalam makalah ini akan diinformasikan hasil kajian di perairan Arafura yang menunjukkan daerah penangkapan udang dan berbagai jenis ikan demersal. Perairan Arafura merupakan bagian wilayah perpanjangan sahul shelf yang mempunyai kedalaman relatif dangkal (rata-rata $<50 \mathrm{~m}$ ), kondisi perairan dikenal dengan tingkat kesuburan tinggi serta menopang kekayaan sumber daya udang dan ikan demersal cukup berlimpah. Oleh karena itu, di perairan ini menjadi daerah penangkapan ikan cukup potensial yang padat oleh berbagai alat tangkap terutama sejak dioperasikan jaring pukat dasar (bottom trawl) sejak tahun 1969 (Naamin \& Sudrajad, 1975). Informasi tentang indikasi ada kelebihan tangkap (over fising) akibat padat jumlah alat tangkap pukat dasar sudah sering diinformasikan, namun yang mengaitkan dengan kondisi kerusakan substrat pada dasarnya belum banyak yang mengungkapkan. Kerusakan substrat dasar menurut Fresi et al. (1983) akan berpengaruh langsung terhadap struktur komunitas organisme bentos baik secara struktural (menyangkut komposisi dan diversitas) maupun terhadap parameter fungsional yang menyangkut tentang produktivitas, sehinga secara tidak langsung akan berpengaruh pula terhadap stok sumber daya ikan demersal. Untuk mendukung riset sumber daya ikan demersal di perairan Arafura, maka dalam makalah ini akan diinformasikan tipe sedimen yang menyusun dasar perairan.

\section{Tekstur Dasar}

Berdasarkan pada analisis terhadap 31 contoh sedimen yang diambil dari 31 lokasi stasiun pengamatan, diperoleh 7 macam komponen tekstur sesuai besar ukuran partikel (Tabel 1). Ke-tujuh tekstur tersebut terdiri atas pasir kasar (course sands), pasir sedang (medium sands), pasir halus (fine sands), pasir halus sekali (very fine sands), debu atau lumpur atau lanau (silt), dan liat (clays).

Dari 7 tekstur tersebut apabila dikelompokkan berdasarkan pada jenis, maka diperoleh 3 kelompok tekstur yang menggambarkan struktur sedimen di perairan Arafura. Macam struktur sedimen tersebut terdiri atas pasir (ukuran 0,075 
Tabel 1. Hasil analisis tekstur substrat (\%) pada stasiun pengamatan di dasar perairan Arafura bulan Oktober 2003

\begin{tabular}{|c|c|c|c|c|c|c|c|}
\hline $\begin{array}{l}\text { Stasiun } \\
\text { Station }\end{array}$ & $\begin{array}{l}\text { Pasir kasar } \\
\text { Course sands. }\end{array}$ & $\begin{array}{l}\text { Pasir sedang } \\
\text { Medium sands }\end{array}$ & $\begin{array}{l}\text { Pasir sedang } \\
\text { Medium sands. }\end{array}$ & $\begin{array}{l}\text { Pasir halus } \\
\text { Fine sands }\end{array}$ & $\begin{array}{l}\text { Pasir termalus } \\
\text { Vey fine sands }\end{array}$ & $\begin{array}{l}\text { Debu } \\
\text { Silt }\end{array}$ & $\begin{array}{l}\text { Liat } \\
\text { Ctays }\end{array}$ \\
\hline 1 & 3,15 & 0,01 & 0,57 & 0,98 & 19,22 & 11,14 & 64,93 \\
\hline 2 & 7,85 & 4,10 & 9,16 & 14,15 & 11,46 & 1,79 & 51,49 \\
\hline 3 & 4,51 & 2,37 & 4,70 & 12,26 & 29,07 & 3,19 & 43,89 \\
\hline 4 & 16,46 & 3,84 & 3,66 & 4,91 & 47,70 & 2,91 & 20,53 \\
\hline 5 & 34,63 & 5,95 & 8,62 & 9,38 & 20,46 & 2,21 & 18,74 \\
\hline 6 & 71,99 & 3,12 & 4,87 & 3,11 & 4,28 & 2,38 & 10,26 \\
\hline 7 & 31,71 & 3,51 & 6,38 & 5,35 & 4,86 & 1,95 & 46,25 \\
\hline 8 & 0,32 & 0,21 & 0,75 & 8,13 & 14,83 & 6,27 & 69,49 \\
\hline 9 & 2,35 & 0,76 & 2,72 & 14,03 & 26,54 & 3,64 & 49,96 \\
\hline 10 & 0,31 & 0,01 & 0,66 & 1,15 & 22,49 & 13,03 & 62,35 \\
\hline 11 & 0,39 & 0,07 & 0,25 & 2,16 & 42,91 & 4,57 & 49,66 \\
\hline 12 & 19,18 & 1,59 & 3,38 & 44,53 & 13,61 & 1,37 & 16,34 \\
\hline 13 & 1,25 & 1,73 & 11,67 & 28,23 & 17,49 & 2,70 & 36,93 \\
\hline 14 & 4,25 & 3,28 & 17,25 & 21,98 & 15,79 & 2,99 & 34,47 \\
\hline 15 & 0,98 & 0,22 & 1,19 & 5,77 & 34,81 & 9,48 & 47,55 \\
\hline 16 & 1,98 & 1,01 & 2,78 & 23,04 & 29,66 & 4,10 & 37,44 \\
\hline 17 & 0,10 & 0,05 & 0,24 & 0,54 & 4,06 & 7,31 & 87,71 \\
\hline 18 & 4,79 & 2,29 & 12,87 & 30,48 & 11,72 & 1,68 & 36,17 \\
\hline 19 & 1,42 & 0,22 & 4,83 & 21,71 & 16,93 & 2,57 & 52,32 \\
\hline 20 & 0,00 & 0,32 & 0,48 & 1,23 & 4,29 & 2,75 & 90,94 \\
\hline 21 & 0,41 & 0,07 & 0,34 & 0,32 & 1,68 & 1,15 & 96,03 \\
\hline 22 & 6,60 & 0,39 & 1,88 & 1,79 & 4,05 & 2,31 & 82,99 \\
\hline 23 & 0,16 & 0,18 & 0,61 & 3,50 & 0,03 & 1,48 & 94,05 \\
\hline 24 & 1,01 & 0,09 & 0,84 & 4,33 & 11,97 & 2,20 & 79,57 \\
\hline 25 & 5,01 & 0,52 & 1,72 & 0,19 & 14,00 & 1,77 & 76,79 \\
\hline 26 & 8,46 & 1,58 & 6,37 & 15,30 & 17,15 & 1,08 & 50,05 \\
\hline 27 & 39,34 & 3,33 & 21,20 & 25,56 & 7,60 & 0,85 & 2,12 \\
\hline
\end{tabular}

sampai dengan $0,8 \mathrm{~mm}$ ), debu atau lumpur (ukuran $0,053 \mathrm{~mm}$ ), dan liat (ukuran $<0,053 \mathrm{~mm}$ ) di mana masing-masing lokasi stasiun menunjukkan komposisi yang bervariasi (Tabel 2).

\section{Tipe Sedimen}

Pada umumnya struktur substrat dasar di seluruh stasiun pengamatan memiliki 3 komponen utama yaitu pasir, lumpur, dan liat. Komponenkomponen tersebut apabila diklasifikasikan berdasarkan pada skala segitiga Shepard menurut Shepard (1954), maka dihasilkan tipe sedimen seperti tampak pada Tabel 3.

Tampak bahwa sebagian besar stasiun didominasi oleh tipe sedimen berliat, liat berpasir, dan sebagian kecil pasir dan lempung. Sedimen berliat ditemukan 13 stasiun dari total 27 stasiun pengamatan atau mendominasi $48 \%$, sedangkan liat berpasir mendominasi $29,6 \%$, dan lempung berpasir $11 \%$. Tipe pasir dijumpai sangat jarang. Pada umumnya sedimen berliat ditemukan pada stasiun-stasiun mulai nomor ke-21 kemudian berturut-turut sampai dengan stasiun 29 , di mana posisi berada dekat dengan Muara Digul.

\section{Distribusi Tekstur}

Pola sebaran tekstur sedimen di dasar perairan Arafura tampak pada Gambar 2, 3, dan 4. Sedimen liat sebagian besar tampak menempati daerah dekat pantai dan cenderung dominan di sekitar Muara Digul, sebaliknya sedimen pasir menempati daerah tengah menjauhi pantai.

Dilihat dari dominasi sedimen dan pola distribusi, tampak bahwa tipe sedimen yang membentuk perairan ini diduga banyak dipengaruhi oleh aliran Sungai. Dugaan tersebut didasarkan pada beberapa argumen menurut Odum (1971); Davies (1980); Krumbein \& Sloss (1963), bahwa sungai-sungai membawa partikelpartikel lumpur mengalir menuju muara dan akhirnya mengendap di dasar laut membentuk tipe sedimen tertentu. Jenis tipe sedimen tersebut berkaitan erat dengan faktor kuat arus dan ombak di laut, apabila kondisi arus sangat kuat maka partikel-partikel yang mengendap akan didominasi oleh partikel yang ukurannya relatif lebih besar. sebaliknya bila kekuatan arus tersebut lemah maka partikel yang berukuran relatif halus akan mendominasi di dasar perairan.

Berdasarkan pada pengamatan kondisi arus di 
Tabel 2. Kondisi substrat dasar di perairan Arafura, bulan Oktober 2003

\begin{tabular}{|c|c|c|c|c|}
\hline \multirow{2}{*}{ Starin } & \multirow{2}{*}{ Gevolaman } & \multicolumn{3}{|c|}{ 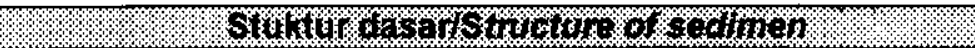 } \\
\hline & & Pasirowors WO & 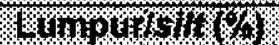 & 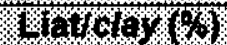 \\
\hline 1 & 41,4 & 23,93 & 11,14 & 64,93 \\
\hline 2 & 43,2 & 46,73 & 1,79 & 51,49 \\
\hline 3 & 48,8 & * & * & * \\
\hline 4 & 40,0 & 52,91 & 3,19 & 43,89 \\
\hline 5 & 33,6 & 76,56 & 2,91 & 20,53 \\
\hline 6 & 30,0 & 79,05 & 2,21 & 18,74 \\
\hline 7 & 23,0 & 87,37 & 2,38 & 10,26 \\
\hline 8 & 23,0 & 51,80 & 1,95 & 46,25 \\
\hline 9 & 24,0 & 24,24 & 6,27 & 69,49 \\
\hline 10 & 30,0 & 46,41 & 3,64 & 49,96 \\
\hline 11 & 25,0 & 24,62 & 13,03 & 62,35 \\
\hline 12 & 24,0 & 45,78 & 4,57 & 49,66 \\
\hline 13 & 25,3 & 82,29 & 1,37 & 16,34 \\
\hline 14 & 31,6 & 60,37 & 2,70 & 36,93 \\
\hline 15 & 30,0 & * & * & * \\
\hline 16 & 33,0 & 62,55 & 2,99 & 34,47 \\
\hline 17 & 33,5 & 42,97 & 9,48 & 47,55 \\
\hline 18 & 31,0 & 58,46 & 4,10 & 37,44 \\
\hline 19 & 37,0 & 4,99 & 7,31 & 87,71 \\
\hline 20 & 34,0 & 62,15 & 1,68 & 36,17 \\
\hline 21 & 25,0 & 45,11 & 2,57 & 52,32 \\
\hline 22 & 26,0 & $\star$ & * & * \\
\hline 23 & 29,0 & * & * & * \\
\hline 24 & 21,0 & 6,32 & 2,75 & 90,94 \\
\hline 25 & 20,0 & 2,82 & 1,15 & 96,03 \\
\hline 26 & 18,0 & 14,70 & 2,31 & 82,99 \\
\hline 27 & 23,0 & 4,47 & 1,48 & 94,05 \\
\hline 28 & 27,5 & 18,23 & 2,20 & 79,57 \\
\hline 29 & 33,5 & 21,44 & 1,77 & 76,79 \\
\hline 30 & 39,5 & 48,87 & 1,08 & 50,05 \\
\hline 31 & 39,0 & 97,03 & 0,85 & 2,12 \\
\hline
\end{tabular}

perairan Arafura saat dilakukan pengambilan contoh sedimen, menunjukkan bahwa kecepatan arus rata-rata relatif lemah $\left(0,41 \mathrm{~m} \mathrm{dt}^{-1}\right)$ dan kondisi tersebut diduga kuat mendukung proses pengendapan partikel halus yaitu tekstur liat yang tampak mendominasi di sekitar muara Sungai Digul. Dengan demikian, dapat dikatakan bahwa di perairan ini telah terjadi pengendapan liat yang diduga berasal dari sungai-sungai yang bermuara di sekitar perairan Arafura, terutama Sungai Digul.

Tabel 3. Tipe sedimen pada stasiun pengamatan di perairan Arafura, bulan Oktober 2003

\begin{tabular}{|c|c|c|c|c|}
\hline \multirow{2}{*}{ Stustion } & \multicolumn{3}{|c|}{ 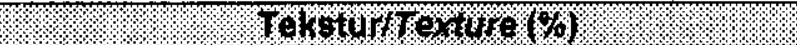 } & \multirow{2}{*}{ 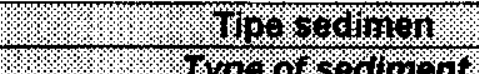 } \\
\hline & Xysints inds: & 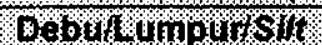 & Govelays & \\
\hline 1 & 23,93 & 11,14 & 64,93 & Berliat/Clays \\
\hline 2 & 46,73 & 1,79 & 51,49 & Berliat/Clays \\
\hline 3 & & & & \\
\hline 4 & 52,91 & 3,19 & 43,89 & Liat berpasir/Clay sands \\
\hline 5 & 76,56 & 2,91 & 20,53 & Lempung berpasir/Clay sands \\
\hline 6 & 79,05 & 2,21 & 18,74 & Lempung berpasir/Clay sands \\
\hline 7 & 87,37 & 2,38 & 10,26 & Pasir berlempung/Sand clays \\
\hline 8 & 51,80 & 1,95 & 46,25 & Liat berpasir/Clay sands \\
\hline 9 & 24,24 & 6,27 & 69,49 & Berliat/Clays \\
\hline 10 & 46,41 & 3,64 & 49,96 & Liat berpasir/Clay sands \\
\hline
\end{tabular}


Tabel 3.

Lanjutan

\begin{tabular}{ccccl}
\hline Stasiun & & Tekstur/Texture $\%$ & & \multicolumn{1}{c}{ Tipe sedimen } \\
Station & Pasir/Sands & Debultumpurlsit & LiatClays & \multicolumn{1}{c}{ Type of sediment } \\
\hline 11 & 24,62 & 13,03 & 62,35 & Berliat/Cays \\
12 & 45,78 & 4,57 & 49,66 & Liat berpasir/Clay sands \\
13 & 82,29 & 1,37 & 16,34 & Pasir berlempung/Sand clays \\
14 & 60,37 & 2,70 & 36,93 & Liat berpasir/Clay sands \\
15 & & & & \\
16 & 62,55 & 2,99 & 34,47 & Lempung berpasir/Clay sands \\
17 & 42,97 & 9,48 & 47,55 & Berliat/Clays \\
18 & 58,46 & 4,10 & 37,44 & Liat berpasir/Clay sands \\
19 & 4,99 & 7,31 & 87,71 & Berliat/Clays \\
20 & 62,15 & 1,68 & 36,17 & Liat berpasir/Clay sands \\
21 & 45,11 & 2,57 & 52,32 & Berliat/Clays \\
22 & & & & \\
23 & & & & \\
24 & 6,32 & 2,75 & 90,94 & Berliat/Clays \\
25 & 2,82 & 1,15 & 96,03 & Berliat/Clays \\
26 & 14,70 & 2,31 & 82,99 & Berliat/Clays \\
27 & 4,47 & 1,48 & 94,05 & Berliat/Clays \\
28 & 18,23 & 2,20 & 79,57 & Berliat/Clays \\
29 & 21,44 & 1,77 & 76,79 & Berliat/Clays \\
30 & 48,87 & 1,08 & 50,05 & Liat berpasir/Clay sands \\
31 & 97,03 & 0,85 & 2,12 & Berpasir/Sands \\
\hline
\end{tabular}

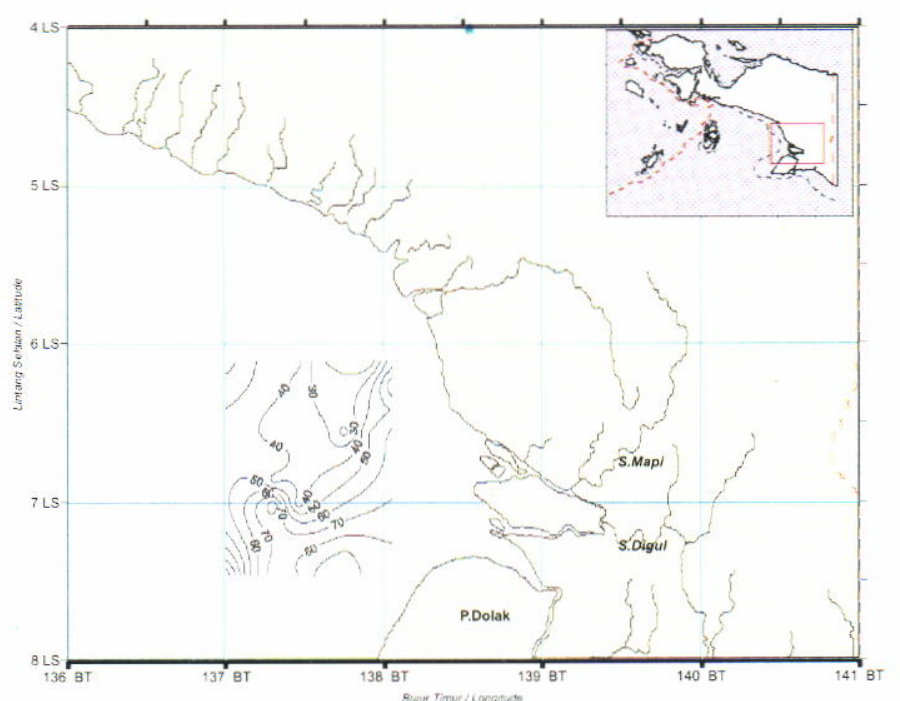

Gambar 2. Pola sebaran tekstur liat (\%) di perairan Arafura, bulan Oktober 2003. 


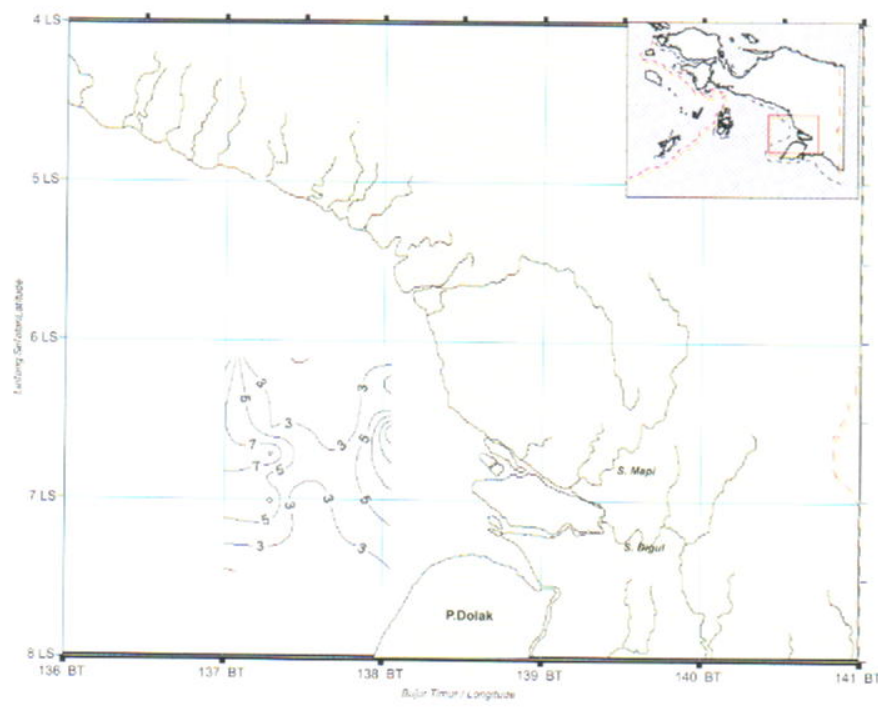

Gambar 3. Pola sebaran tekstur debu atau lumpur (\%)di perairan Arafura, bulan Oktober 2003.

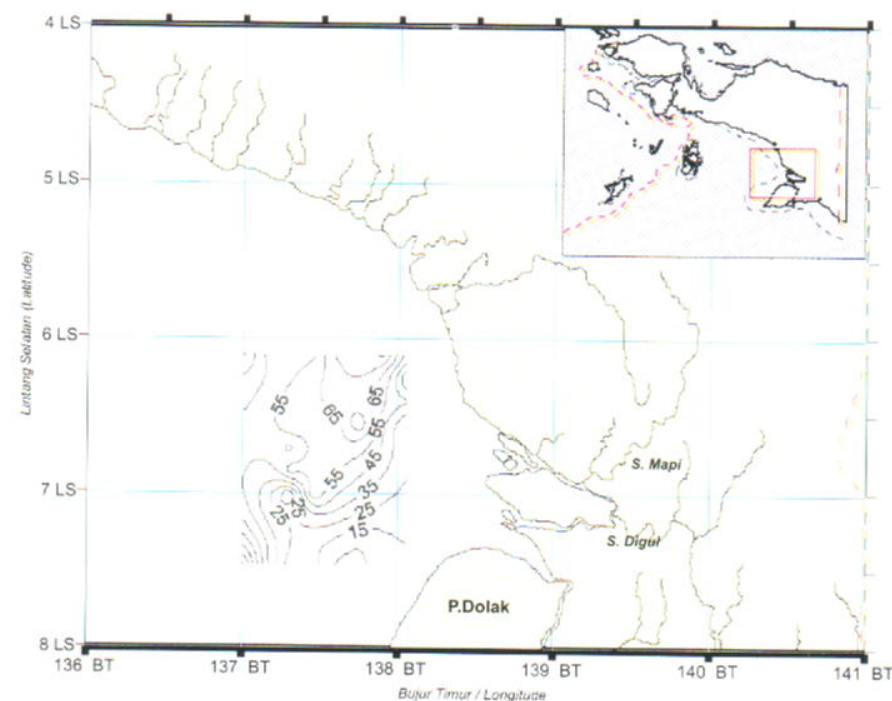

Gambar 4. Pola sebaran tekstur pasir (\%) di perairan Arafura, bulan Oktober 2003.

\section{KESIMPULAN}

Sedimen yang menyusun dasar perairan Arafura didominasi oleh tipe berliat $(48 \%)$ yang menyebar pada sebagian besar perairan dekat pantai terutama sekitar muara Sungai Digul, sedangkan pada perairan menjauhi pantai, pada umumnya berupa campuran liat berpasir yang mendominasi sekitar $29,6 \%$, lempung berpasir $11 \%$, dan yang bertipe pasir relatif jarang.

\section{DAFTAR PUSTAKA}

Davies, J. L. 1980. geographical variation in coastal development. Lowe \& Brydone Printers Limited. The Ford. Nort Folk: 212 pp.
Fresi, E., M. C., Gambi, S. Focardi, R. Barbgagli, F. Baldi, \& L. Falcial. 1983. Benthic community and sediment types: A structural analysis. Mar. Ecol. 4 (2): 101-121.

Hermanto, B., A. Suwartana, \& Suhartati. 1987. Komposisi sedimen perairan Sorong, Selat Sele, Irian Jaya, oseanologi di Indonesia. Pusat Penelitian dan Pengembangan Oseanologi. Lembaga IImu Pengetahuan Indonesia. Jakarta. No.22: 45-59.

Krumbein, W. C. \& L. L. Sloss. 1963. Stratigraphy and sedimentation. M. H. Freemen and Company. San Fransisco: 460 pp.

Martosubroto, P. \& M. Badrudin. 1984. Notes of 
the status of the demersal resouirce of the north coast of Java. IPFC. Bangkok (3): 1-2.

Naamin, N. \& A. Sudradjad. 1975 Progress report of the Arafura shrimp fishery. Laporan Penelitian Perikanan Laut. Jakarta. Lembaga Penelitian Perikanan Laut. No.2. Hal: 45.

Nybaken, J. W. 1988. Biologi laut: Suatu pendekatan ekologis. Alih Bahasa H. M. Eidman et al. Cetakan 1. Gramedia. Jakarta. 480 hal.

Ongkosongo, O. S. R., Subardi, Sumiati, L. Effendi, A. Sunardi, \& P. Hamidjojo. 1979. Sedimen dasar Teluk Jakarta, Teluk Jakarta, pengkajian fisika, kimia biologi, dan geologi. A. Nontji \& Djamali (ed). LON. Lembaga IImu Pengetahuan Indonesia. Jakarta. Hal: 375-407.

Odum, E. P. 1971. Fundamental of ecology. $3^{\text {rd }}$ Edition. W. B.Sounders Comp. Phildelphia. 574 hal.
Rosyid, A. 1995. Penelitian tentang kedalaman dan tekstur dasar perairan terhadap penyebaran ikan demersal di pantai utara Jawa Tengah (Rembang dan Kendal). Laporan Hasil Penelitian. Program Studi IImu Kelautan. Universitas Diponegoro. Semarang. $23 \mathrm{~h}$.

Soedharma, D. 1972. Hubungan antara tekstur dasar perairan (substrat) dengan distribusi udang famili Peneidae di perairan Kalimantan Selatan dan Timur. Laporan Penelitian Perikanan Laut. No.1: 80-90 h.

Shepard, F. P. 1954. Nomenclature based on sand silt clay ratio. Journal Sed.Petrology. (24): 151158.

Widodo, J. 1979. A check list of fisheries collected by Mutiara IV. Contribution of Demersal Fisheries Project. Lembaga Penelitian Perikanan Laut. Jakarta. (I) : 51-77. 
